\title{
BJMHR
}

British Journal of Medical and Health Research

Journal home page: www.bjmhr.com

\section{Efficacy of Topical Brimonidine Versus Timolol to prevent Intraocular Pressure Elevation after ND: Yag Laser Capsulotomy.}

\author{
Smita K. Kadu ${ }^{1}$, Neha Chandrashekhar Yerawar ${ }^{2 *}$ \\ 1.Narayan nagar, Rajendra Colony Road, Amravati 444606 \\ 2. B1/101, Raghukul CHS, Parsik Nagar, Kalwa, Thane Maharashtra-400605
}

\begin{abstract}
The aim of the study is to examine the preventive effects of drugs given before Nd:YAG capsulotomy to prevent transient IOP spike occurring after the procedure.130 patients were included in the study and their IOP were recorded one hour prior to the procedure and then after the procedure at predetermined timings. Patients were divided into two groups based on the drop brimonidine or timolol instilled in their eyes before the procedure. The changes in the IOP were compared in between the two groups, In the results we found that both the drugs lowered IOP after two hours with brimonidine having values $12.86 \pm 3.35$ and timolol with $13.35 \pm 5.25$. However, both the drugs lowered the IOP to values below the recorded ones at the commencement of the procedure but did not show any significant difference amongst themselves. Hence, to summarize the study we found that both the drugs decrease the transient IOP spike so as to prevent chances of glaucoma development in the patient.
\end{abstract}

Keywords: Nd: YAG- Neodymium Yttrium-Aluminum garnet, PCO-Posterior capsular opacification, IOP-Intraocular pressure. 


\section{INTRODUCTION}

Posterior capsule opacification (PCO) is the most common delayed complication of cataract surgery. The incidence of PCO was reported to be 20.7 per cent at two years and 28.5 per cent at 5 years after cataract surgery. ${ }^{1}$

Marcantonio observed that posterior capsule opacification results from growth and transdifferentiation of lens epithelial cells left on anterior capsule at the time of cataract surgery.

Lens epithelial cells (LECs) left behind in the capsular bag after any type of extracapsular cataract surgery are mainly responsible for posterior capsule opacification development. ${ }^{2}$

Clinically there are 2 morphological types of PCO, the fibrosis type and the pearl type. Fibrosis type posterior capsule opacification is caused by the proliferation and migration of lens epithelial cells, which undergo epithelial to mesenchymal transition, resulting in fibrous metaplasia and leading to significant visual loss by producing folds and wrinkles in posterior capsule. $^{3}$

Pearl type posterior capsule opacification is caused by lens epithelial cells located at the equatorial lens region (lens bow) causing regeneration of crystalline expressing lenticular fibres and forming Elschnig pearls and Soemmering ring, responsible for most cases of posterior capsule opacification related visual loss. ${ }^{4,5}$

In the early 1980s, the application of Neodymium: Yttrium-Aluminium-Garnet(Nd: YAG) laser capsulotomy as treatment for posterior capsular opacity was presented by Aron-Rosa and Fankhauser. Nd-YAG laser capsulotomy showed itself to be an effective alternative to surgical intervention, avoiding such complications as endophthalmitis and vireous loss. ${ }^{6,7}$

$\mathrm{Nd}$ :YAG laser capsulotomy is accepted as standard treatment for posterior capsule opacification, it is not without complications, some of which can be sight threatening such as retinal oedema and detachment. Studies have described damages in the IOL, increased IOP, glaucoma retinal haemorrhages, iritis, vitreous prolapse, corneal injury, pupil blockage, hyphema, cystoid macular oedema, retinal detachment, IOL dislocation or exacerbation of endophthalmitis. ${ }^{8}$

The reported incidence of IOP elevation after Nd: YAG laser capsulotomy varies from $39 \%$ to $77 \%$. Considering the high incidence of IOP rise with laser capsulotomy, prophylaxis for post laser IOP elevation has become a necessity.

Brimonidine is a selective alpha 2 adrenergic agonist which lowers IOP by decreasing the aqueous humour production and increasing the uveoscleral flow. It has its peak of action at 3$4 \mathrm{hrs}$. Timolol is a non-selective beta blocker that decreases intraocular pressure by decreasing aqueous production. Its onset of action occurs after10-20 minutes of instillation and lasts for at least 24 hrs. with peak action at 2-3 hours. 
Our study aims to find out if there is a significantly relatable difference in the values of IOP changes if the patients are instilled with drugs prior to the procedure. Hence causing a decrease amount of IOP rise post the procedure.

\section{MATERIALS AND METHOD}

A randomized clinical trial was conducted on patients who underwent cataract extraction with PCIOL implantation and presented with posterior capsular opacification. It was a single blinded study that was carried out in the department of ophthalmology in Dr Panjabrao Deshmukh Medical College, India for period of 18 months after approval from the Ethical committee.

All patients who underwent a posterior capsular opacity after extracapsular cataract extraction were included in the study although. Certain patients were excluded from the study like those having glaucoma, any active inflammation or infection, any history of allergy to brimonidine or timolol and known cases of bronchial asthma, respiratory distress, atopy and immune compromised status.

The patients evaluated in the study were randomized and allocated alternatively into odd and even groups. A sample size of 130 patients was finalized and divided into 65 individuals in each group. All patients were given a serial number and based on their numbers they were categorized into odd and even groups. The groups being made, were instilled with drops $1 \mathrm{hr}$. before the procedure. Thus, the odd group was instilled with brimonidine 0.1 per cent and the even group was instilled with timolol 0.5 per cent. The intraocular pressure was measured $1 \mathrm{hr}$. before the procedure, immediately after the procedure and then 1 and 2 hrs. later respectively. Data was statistically analyzed using descriptive and inferential statistics such as Chi square test, Student's paired and unpaired t-test. The results were considered statistically significant when $\mathrm{P}<0.05$. Data was analyzed using SPSS 24.0 version.

\section{RESULTS AND DISCUSSION}

In all, 130 patients were including in the study. The mean age of patients studied was $60.52 \pm$ 5.73 with the range from $48-75$ years of age. Brimonide group had a mean of $61.82 \pm 4.49$ and

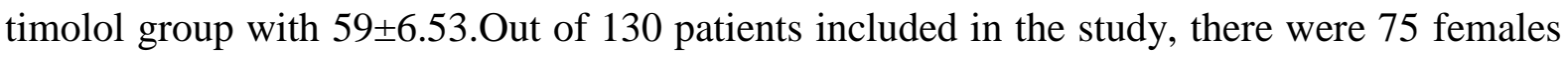
(57.7\%) and 55(42.3\%) males. The brimonidine group had 26 males and 39 females while the timolol group had 29 males and 36 females showing no statistical difference. IOP levels were calculated at baseline in both the groups. (Figure: 1,2) These were taken one hour prior to the procedure and were $14 \pm 3.49$ (Range 10-22) while in the timolol group they were $14 \pm 3.26$ (Range10-24). Immediately after the procedure of Nd:YAG readings were taken.(Table:1) The mean values were $12.70 \pm 2.43$ and $14.32 \pm 3.66$ for the brimonidine and timolol group respectively. An unpaired t-test showed a significant difference between these values, with $t$ value 2.96 and $\mathrm{P}$ value of $0.004(\mathrm{p}<0.05)$. 


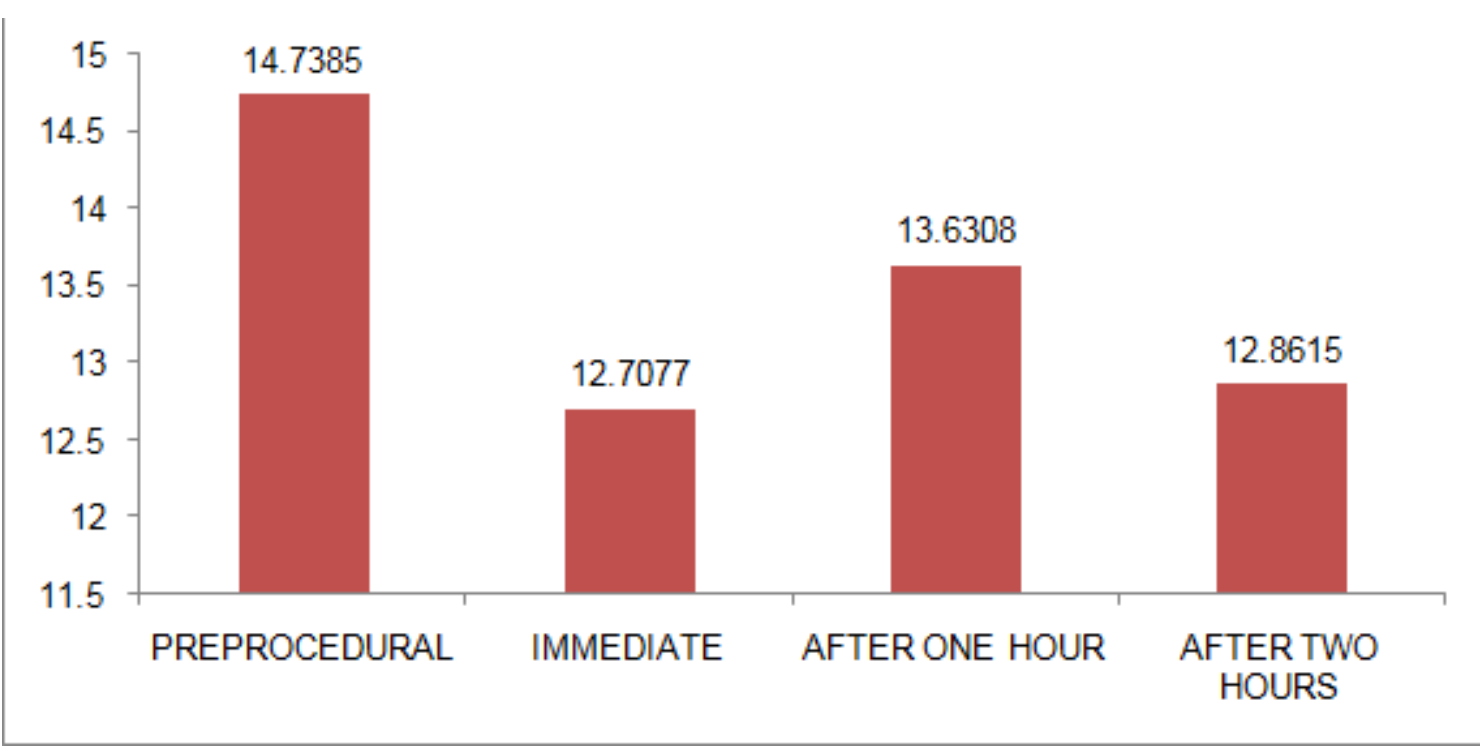

Figure 1: Mean IOP in the Brimonidine group

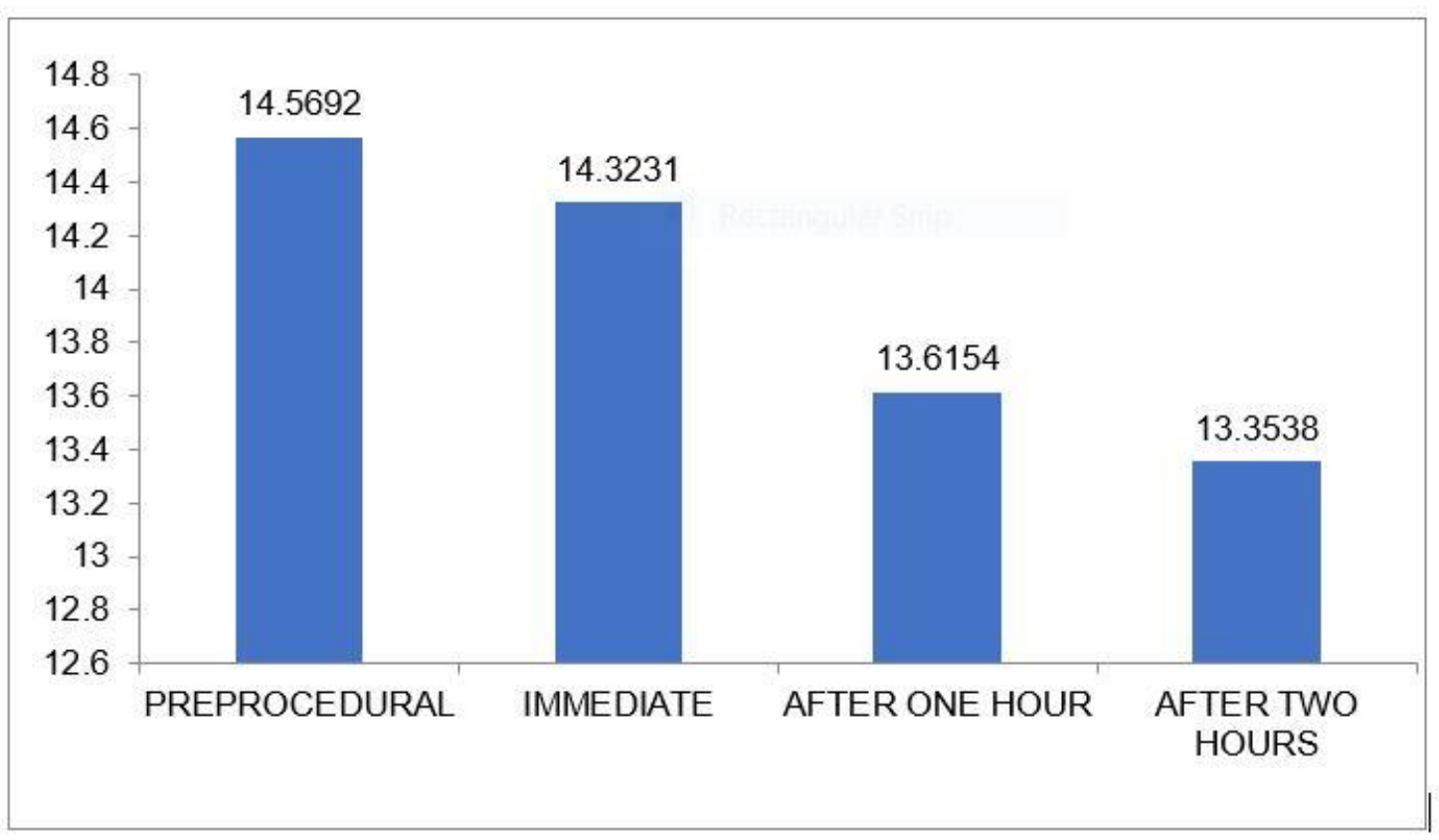

Figure 2: IOP changes within the timolol group

In a similar manner, the values after one hour and two hours of the procedure were procured. The mean value for brimonidine group one hour post the procedure was $13.63 \pm 4.24$ and for timolol group was $13.61 \pm 3.55$. The last values were taken two hours after the completion of the procedure. Brimonidine group had a mean IOP record of $12.86 \pm 3.35$ and timolol with 13.35 \pm 5.25 . (Table: 2 ) Both the readings in the groups were not statistically significant.

Table 1: Post Procedure Immediate IOP Statistics

\begin{tabular}{lllllll}
\hline Group & N & Mean & Std. Deviation & t-test & P value & Association \\
\hline Brimonidine & 65 & 12.7077 & 2.43492 & 2.96 & 0.004 & Significant \\
Timolol & 65 & 14.3231 & 3.66191 & & & \\
\hline
\end{tabular}


Table 2: Overall statistics

\begin{tabular}{lllllll}
\hline $\begin{array}{l}\text { Sr. } \\
\text { No. }\end{array}$ & $\begin{array}{l}\text { Parameters for } \\
\text { analysis }\end{array}$ & $\begin{array}{l}\text { Group 1 } \\
\text { Brimonidine }\end{array}$ & $\begin{array}{l}\text { Group 2 } \\
\text { Timolol }\end{array}$ & P value & $\begin{array}{l}\text { Statistical test } \\
\text { used }\end{array}$ & Interpretation \\
\hline 1 & Age & $61.82 \pm 4.48$ & $59.23 \pm 6.52$ & $\begin{array}{l}\mathrm{X}^{2}=16.03 \\
\mathrm{P}<0.01\end{array}$ & Chi square test & Significant \\
& & & & & \\
2 & Sex & $40 \%$ & $44.62 \%$ & $\mathrm{X}^{2}=0.28$ & Chi square test & Not significant \\
& Male & $60 \%$ & $55.38 \%$ & $\mathrm{P}=0.59$ & & \\
& Female & $14.73 \pm 3.49$ & $14.56 \pm 3.26$ & 0.776 & Unpaired t test & Not significant \\
3 & Pre-procedural & $12.70 \pm 2.43$ & $13.61 \pm 3.55$ & 0.004 & Unpaired t test & Significant \\
4 & Post- procedural: & $12.53 \pm$ & & \\
& Immediate & $13.63 \pm 4.24$ & $13.61 \pm 3.55$ & 0.982 & Unpaired t test & Not significant \\
5 & One hour & $12.86 \pm 3.35$ & $13.35 \pm 5.25$ & 0.525 & Unpaired t test & Not significant \\
\hline
\end{tabular}

\section{DISCUSSION}

Posterior capsular opacification (PCO) is a frequent complication of cataract surgery with posterior chamber intraocular lens implantation ${ }^{9}$. It varies from 7 per cent to 31 per cent, by 2 years postoperatively ${ }^{10}$. Standard treatment of PCO consists of making an opening in the central part of posterior capsule ${ }^{11}$.

$\mathrm{Nd}$ :YAG laser posterior capsulotomy is the treatment of choice for the PCO. This procedure is non-invasive, relatively safer, less time consuming and free from infections but has been associated with complications, like raised intraocular pressure $(42.85 \%){ }^{12}$, IOL pitting, cystoid macular oedema $(4.1 \%)$ and retinal detachment $(2.5 \%)^{13-16}$.

Our study focused on the transient increase in the IOP post the procedure and aimed at reducing it. This transient rise in IOP was also seen by studies done by Slomovic and Parrish et.al. ${ }^{17}$ and Flohret.al. ${ }^{18}$. Hence to curb this transient rise in IOP certain IOP lowering drugs were given before the procedure as seen in studies done by Simsek S et.al. ${ }^{19}$ and Ladas ID, Baltazis $\mathrm{S}$ et.al. ${ }^{20}$. Hence the patients in our study were randomly assigned into two groups, instilled with either of the two drugs that is brimonidine or timolol an hour prior to procedure and the IOP values were recorded to compare their effects.

Nd YAG laser capsulotomy can cause short and long term IOP elevations. Proposed mechanisms include effects to ciliary body caused by laser shock waves, neurohumoral increase in the IOP, structural effects of laser energy on sodium hyaluronate of the vitreous and finally mechanical blockage of trabecular meshwork with debris from disrupted posterior capsule $^{21,22}$.

The two groups had a mean age of $60.523 \pm 5.73$ with the mean age for the Group 1 being $61.81 \pm 4.48$ and Group 2 was $59.29 \pm 6.52$. Sex distribution of the 130 patients consisted of 75 females and 55 males and both the groups had an equally matched demographic of age.

The IOP readings were taken on a Goldmann Applanation Tonometer before and after the procedure. In the Group 1 where in Brimonidine was instilled. The mean values found were 
$14.738 \pm 3.492,12.707 \pm 2.434,13.631 \pm 4.241$ and $12.861 \pm 3.535$ as the pre-procedural and post-procedural immediate, one hour and two-hour values respectively. The paired t-test was applied to check for significance within the group and the $\mathrm{P}$ value was found significant that is $\mathrm{P}<0.001$. Such results were also seen in the studies done by Gartaganis et.al. ${ }^{23}$ and Deepika Singhal, Roopali Desai et.al. ${ }^{24}$ Which suggests that IOP rise post Nd:YAG capsulotomy is curbed by Brimonidine drop instillation.

Similar findings in the Group 2 taken before the procedure are $14.569 \pm 3.264$ and the postprocedure values are $14.323 \pm 3.661,13.615 \pm 3.551$ and $13.353 \pm 5.254$ for the immediate, one hour and two-hour values respectively. The paired t-test was applied here as well and a significant $\mathrm{P}$ was found. These findings were also seen in studies done by Boen Tan TN et.al. and Manav Singh, Nidhi Sharma et.al. ${ }^{25,26}$

While comparing the values of IOP between the two groups unpaired t-test was applied to check for significance. In the initial pre-procedural IOP values between brimonidine and timolol the mean values were $14.738 \pm 3.492$ and $14.569 \pm 3.264$ respectively. The $t$-value found was 0.285 with a $\mathrm{P}$ value of 0.776 , hence stated as insignificant. This means that both the groups had a significantly similar IOP baseline mean value and were not statistically different.

The procedure was undertaken and immediately after the values recorded on GAT which were $12.707 \pm 2.434$ for brimonidine and $14.323 \pm 3.661$ for timolol. Now, the $t$-value calculated was 2.692 with a $\mathrm{P}$ value of 0.004 which is considered significant. Thus, implying that the IOP rise was prevented immediately after the procedure. Also the difference in the IOP values from the baseline values was found more in the brimonidine group that is 2.001 as compared to a difference of 0.269 in the timolol group. All this leads to the inference that brimonidine has better potential to control the transient rise in IOP as compared to timolol.

The values of IOP were also recorded one hour after the procedure, with $13.630 \pm 4.241$ and $13.615 \pm 3.551$ as the values for brimonidine and timolol. The $t$-value found was 0.022 with a $P$ value of 0.982 which was found to be insignificant statistically. Hence concurring that the two drugs had no significant difference in lowering the IOP after one hour and their values were almost similar.

After two hours the IOP values recorded were $12.861 \pm 3.353$ for brimonidine and $13.353 \pm$ 5.254 for timolol. The unpaired t-test applied got a t-value of 0.637 and had $\mathrm{P}$ value of 0.525 which was again insignificant. This implied that the changes from the baseline IOP was similar in both the groups after two hours of the procedure.

Thus, the findings in our study wherein a transient rise in IOP post capsulotomy is better controlled by brimonidine rather than timolol were in agreement to the findings by studies done 
by Dr M Hemanandini, Dr P Sumathi et.al. ${ }^{27}$ and Amruth Lal Yellamelli, Vibha Florence Baldevet.al. ${ }^{8}$

\section{CONCLUSION}

This conclusion leads us to the inference that IOP rise is a complication seen post Nd:YAG capsulotomy but this rise could be decreased substantially with pre-procedural instillation of drugs. Of the two drugs taken under consideration brimonidine was superior to timolol and hence can be effectively used to curb the IOP rise, thus preventing the patients of any chance of developing glaucoma in the near future.

\section{SUMMARY}

The study aimed to find out if pre-procedural instillation of drugs had a better efficacy to prevent the post procedural rise in IOP. A paired t-test was applied to compare the drugs, brimonidine and timolol for their IOP lowering potentials. The resultant $\mathrm{P}$ value was found significant for both the drugs had potential to lower the transient rise in IOP effectively and none of the values were found to be higher than the initial values before the laser capsulotomy. An unpaired t-test was applied to find the differences between the two groups and the brimonidine group was found to have a greater efficacy in lowering the immediate IOP levels as compared to the timolol group. Although, they had similar potential for lowering IOP after one hour. Similar findings were also seen after two hours. Hence proving that brimonidine was a better drug for pre-procedural instillation to prevent the rise in transient IOP. This study interference could help us prevent the rise in IOP post Nd:YAG capsulotomy which would lead to lesser chances of the patient developing glaucoma later.

\section{REFERENCE}

1. Nakazawa M, Ohtsuki K. Apparent accommodation in pseudophakic eyes after implantation of posterior chamber intraocular lenses. Am J Ophthalmol. 1983 Oct;96(4):435-8. PMID:6624824

2. Marcantonio JM, Vrensen GF. Cell biology of posterior capsularopacification. Eye. 1999 May1;13(3b):484.

3. Shah GR, Gills JP, Durham DG, Ausmus WH. Three thousand YAG lasers in posterior capsulotomies: an analysis of complications and comparison to polishing and surgical discussion. Ophthalmic Surg. 1986 Aug;17(8):473-7. PMID: 3748538.

4. Raj SM, Vasavada AR, Johar SK, Vasavada VA, Vasavada VA. Post- operative capsular opacification: a review. International journal of biomedical science: IJBS. 2007Dec;3(4):237.

5. Saika S Relationship between posterior capsule opacification and intraocular lens biocompatibility. Prog Retin Eye Res 2004;23 (3) 283-305 
6. Aron-Rosa D, Aron JJ, Griesemann M, Thyzel R. Use of the neodymium- YAG laser to open the posterior capsule after lens implant surgery: a preliminary report. American Intra-Ocular Implant Society Journal. 1980 Oct1;6(4):352-4.

7. Wormstone IM. Posterior capsule opacification: a cell biological perspective. Experimental eye research. 2002 Mar1;74(3):337-47.

8. Yellamelli AL, BaldevVF,Batra N,et.al.Effect of topical brimonidine 0.15\% versus timolol $0.5 \%$ to prevent intraocular pressure elevation after $\mathrm{Nd}$; Yag laser capsulotomy. J. Evid. Based Med. Health. 2017;4(55),3365-3368.DOI:10.18410/jebmh/2017/668

9. Winslow RL, Taylor BC. Retinal complications following YAG laser capsulotomy. Ophthalmology 1985;92:785-9.

10. Auffarth G, Brezin A, Caporossi A, Lafuma A, Mendicute J, Berdeaux G, et.al. Comparison of $\mathrm{Nd}$ : YAG capsulotomy rates following phacoemulsification with implantation of PMMA,silicone or acrylic intraocular lenses in four European countries.OphthalmicEpidemiol2004; 11:319-29.

11. Kohnen T, Wang L, Freidman NJ, Koch DD.Complications of cataract surgery. In: Yanoff M, Duker JS, editors. Ophthalmology.Philadelphia: Mosby; 2004.p.381-90.

12. Alimanovic-HalilovicE.[Complications in the posterior eye segmentafterNd:YAG laser capsulotomy]. Med Arh2004; 58:7-9. Bosnian.

13. Rakofsky S, Koch DD, Faulkner JD, Terry SA, Mandell AI, Gross RL, et.al. Levobunolol $0.5 \%$ and timolol $0.5 \%$ to prevent intraocular pressure elevation after $\mathrm{Nd}$ : YAG laser posterior capsulotomy. J Cataract Refract Surg1997;23:1075-80.

14. Alimanovic-Halilovic E. Correlation between eye aperture diameter and complications in the posterior eye segment after Nd-YAG laser capsulotomy. Bosn J Basic Med Sci 2008;8:106-9.

15. Peace health. Nd: YAG laser posterior capsulotomy for cataracts.2009

16. Slomovic AR, Parrish RK 2nd. Acute elevations of intraocular pressure following Nd: YAG laser posterior capsulotomy.Ophthalmology1985; 92:973-6.

17. Flohr MJ, Robin AL, Kelley JS. Early complications following Qswitched neodymium: YAG laser posterior capsulotomy. Ophthalmology 1985; 92:360-3.

18. Simsek S, Ertürk H, Demirok A, Chinal A, Yasar T, Karadenizli C. The effect of 0.25 per centapraclonidine in preventing intraocular pressure elevation after Nd: YAG laser posterior capsulotomy.Eur J Ophthalmol1998; 8:167-72.

19. Ladas ID, Baltatzis S, Panagiotidis D, Zafirakis P, Kokolakis SN, Theodossiadis GP. Topical 2.0\% dorzolamide vs. oral acetazolamide for prevention of intraocular pressure rise after neodymium: YAG laser posterior capsulotomy. Arch Ophthalmol1997;115:1241-4. 
20. Jahn CE, Emke M. Long term elevation of intraocular pressure after neodymium:YAGlase posterior capsulotomy. Ophthalmologica. 1996; 210(2):85-9.

21. Georgalas I, Petrou P, Kalantzis G, Papaconstantinou D, KoutsandreaC,Ladas I. Nd: YAG capsulotomy for posterior capsule opacification after combined clear corneal phacoemulsification and vitrectomy. Therapeutics and clinical risk management. 2009;5:133.

22. Gartaganis SP, Mela EK, Katsimpris JM, Petropoulos JK, Karamanos NK, Koliopoulos JX. Use of topical brimonidine to prevent intraocular pressure elevations following Nd:YAG-laser posterior capsulotomy. Ophthalmic Surg Lasers.1999; 30:647-52.

23. Singhal D, Desai R, Desai S, Shastri, M. and Saxena,D. Use of topical brimonidine to prevent intraocular pressure elevations following $\mathrm{Nd}$ :YAG-laser posterior capsulotomy. Journal of pharmacology \& pharmacotherapeutics. 2011 apr;2(2):104.

24. Singhal D, Desai R, Desai S, Shastri, M. and Saxena,D. Use of topical brimonidine to prevent intraocular pressure elevations followingNd:YAG-laser posterior capsulotomy. Journalof pharmacology\& pharmacotherapeutics. 2011 apr;2(2):104.

25. Boen-Tan TN, Stilma JS. Prevention of IOP-rise following Nd-YAG laser capsulotomy with pre-operative timolol eye-drops and 1 tablet acetazolamide $250 \mathrm{mg}$ systematically. Documentaophthalmologica. 1986 Dec1;64(1):59-67.

26. Singh MD, Sharma N, Jain S. Anterior segment Nd: YAG laser procedures: to study intraocular pressure spikes and their prevention. The Official Scientific Journal of Delhi Ophthalmological Society. 2015 Sep 30;26(2):93-6.

27. Dr M Hemanandini " A Study to Compare The Efficacy of 0.5\% Timolol Eye Drops Versus0.2\% Brimonidine Eye Drops in Management of Rise In Iop Following Nd-Yag Capsulotomy."IOSR Journal of Dental and Medical Sciences (IOSR-JDMS) 16.9 (2017):71-76.

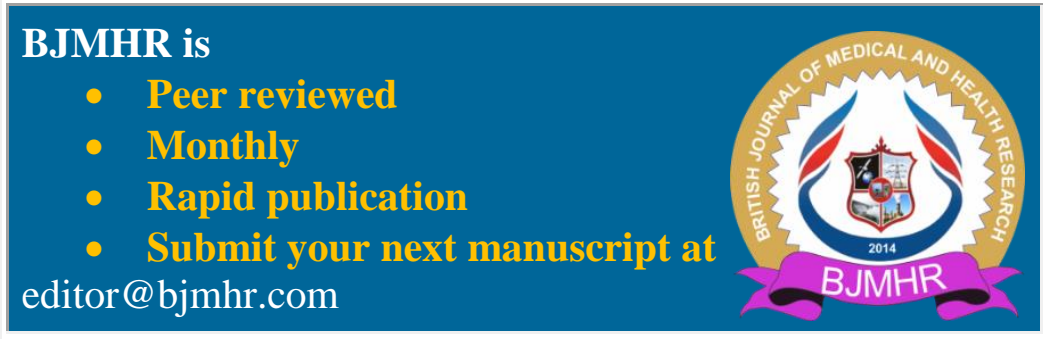

